\title{
Extensive Fixed Drug Eruption Due to Diclofenac
}

*Rudrajit Paul, Gautam Lahiri, Tanmay J. Sau, Kunal Haldar, Rajesh Pandey, Asim Saha

$$
\text { طفح دوائي ثابت منتشر بسبب دواء ديكلوفيناك }
$$

ريدراجيت بول، قواتام ليهيري، تانمي جوتي ساو، كونال هـالدار، راجيش باندي، عاصم ساهـا

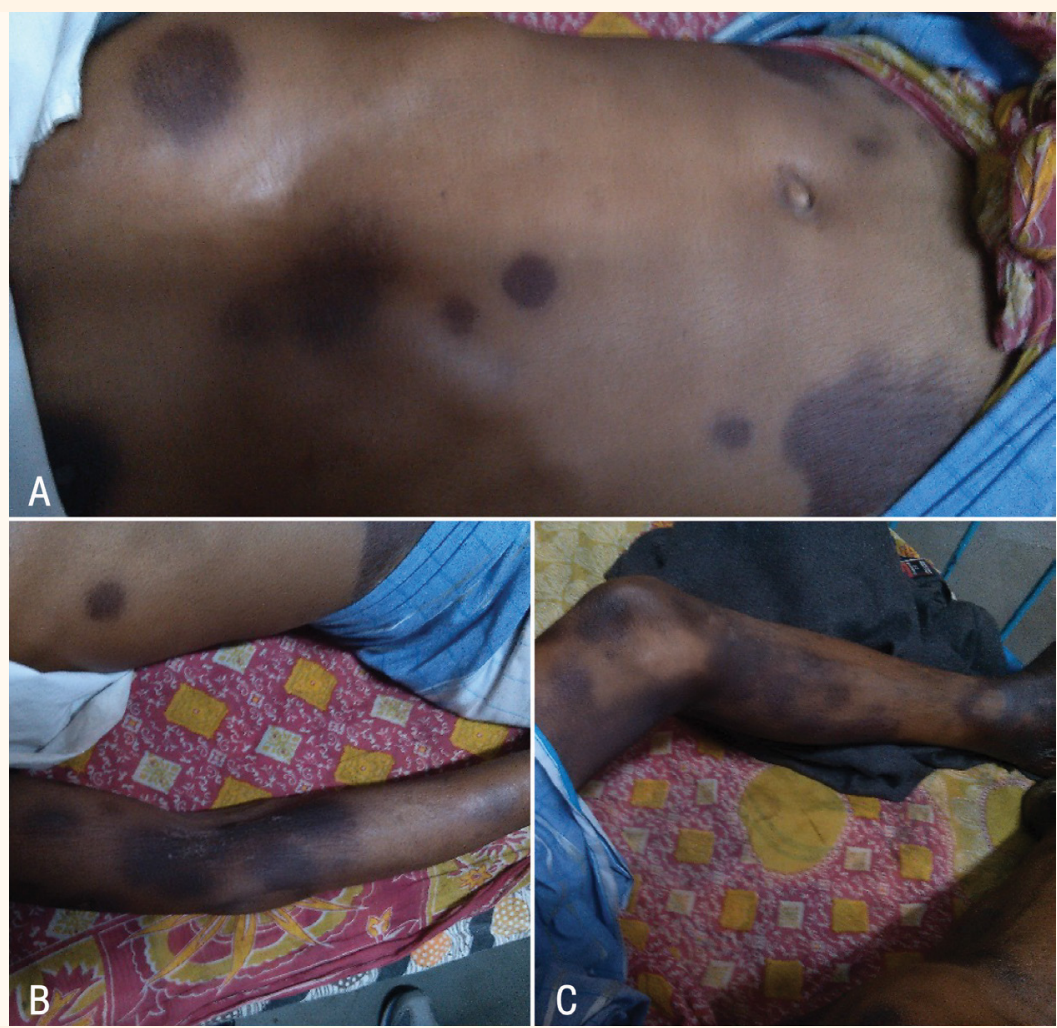

Figure 1: Extensive hyperpigmented patches on the (A) trunk, (B) arms and (C) legs of a 46-year-old man after taking $50 \mathrm{mg}$ of diclofenac three times a day for three days.

A 46-YEAR-OLD MALE CONSTRUCTION WORKER was admitted to a clinic in Kolkata, India, in 2016 with a sudden-onset black rash appearing in patches all over his body. He had sprained his left foot two days previously for which he was prescribed oral diclofenac tablets at a dose of $50 \mathrm{mg}$ three times a day. He had taken three doses of the drug before noticing the skin lesions; however, he continued taking the drug due to the pain and presented to the clinic on the third day when the lesions became extensive. He was not currently taking any other drugs and had no history of similar skin lesions.
On examination, the patient was noted to have darkly pigmented patches on his trunk and both the upper and lower limbs [Figure 1]. The patches covered more than $50 \%$ of his body surface and were nonpruritic and non-tender, with sharply demarcated margins and surrounding erythema. No evidence of mucosal lesions or hair or nail changes was seen. The patient was treated with local emollients and a steroid cream. A skin biopsy revealed interface dermatitis with vacuolar changes. The patient was diagnosed with a fixed drug eruption (FDE) caused by the diclofenac. After 10 days, the patches became scaly and started to desquamate [Figure 2]. 


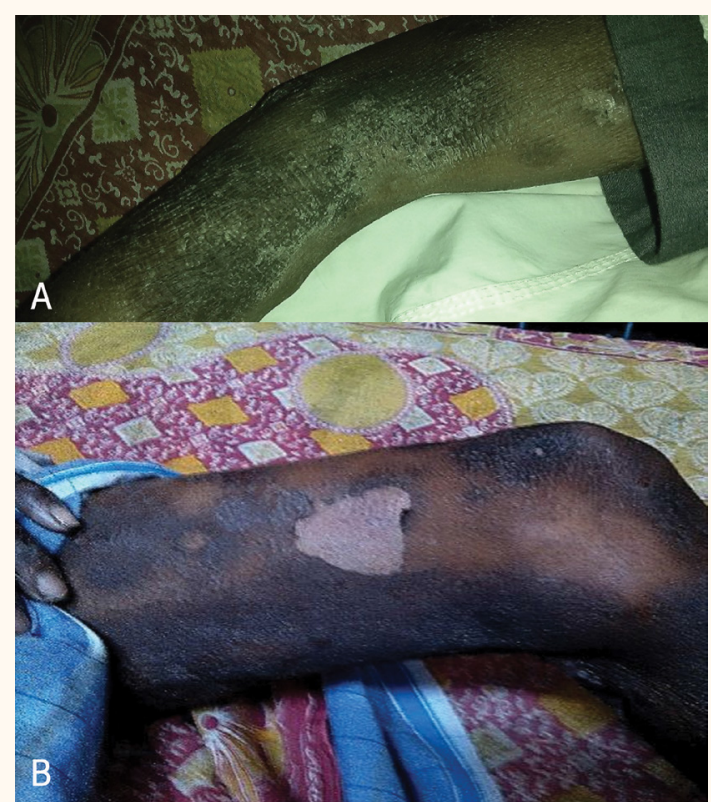

Figure 2: Scaling and desquamation of hyperpigmented patches caused by a diclofenac-induced fixed drug eruption on the (A) arms and (B) legs of a 46-year-old man after 10 days of treatment with local emollients and a steroid cream.

\section{Comment}

FDEs are drug-induced lesions which may appear as patches, vesicles or bullae. ${ }^{1}$ Hyperpigmentation is usually noted at the site of the lesions and recurs at the same sites with subsequent exposure to the drug. ${ }^{1}$ Usually, the lesions are limited to a small area of the skin or mucosa. ${ }^{2}$ However, extensive FDEs have been reported with nonsteroidal anti-inflammatory drugs (NSAIDs), lamotrigine and antibiotics such as vancomycin. ${ }^{3,4}$ Lin et al. reported two patients with NSAID-induced extensive bullous eruptions mimicking Steven-Johnson syndrome. ${ }^{3}$ In another case, an extensive paracetamol-induced eruption was initially suspected to be cellulitis; the patient was treated with antibiotics before new lesions appeared and a skin biopsy led to a FDE diagnosis. ${ }^{5}$ Extensive hyperpigmented dermal patches can sometimes be confused with photoallergic/toxic reactions, café-aulait macules or Addison's disease. ${ }^{4}$

The mainstay of treatment for FDEs is withdrawal of the drug. ${ }^{1,5}$ Although local steroids and/or emollients may be used, systemic therapy is usually not needed. ${ }^{5}$ In general, FDEs are easy to diagnose if the presenting features are typical. However, atypical lesions-such as non-pigmenting FDEs or psoriasiform lesions-may also occur. ${ }^{2}$ As FDEs recur at the same site on subsequent contact with the drug, a diagnosis can be made if there is a previous history of similar lesions at the same site. Sometimes, FDEs may not occur on initial use of the drug and manifest only after a certain dose is attained. ${ }^{1}$ Nonetheless, drug rechallenge is not always ethically possible; a skin biopsy is therefore sufficient to diagnose the condition at first onset. ${ }^{2}$ With diclofenac, various cutaneous reactions can occur after oral or parenteral administration, including anaphylactic reactions, urticaria, exanthema and FDEs. ${ }^{6}$

While there is no definitive histology pattern for FDEs, severe vacuolar interface dermatitis is suggestive of the condition, along with other phenotypic features, such as confluent epidermal necrosis and extension of the infiltrate into the lower half of the dermis., ${ }^{2,5}$ The use of the Naranjo algorithm, particularly the sections regarding previous exposure and readministration, is not always applicable in these cases on ethical grounds. ${ }^{7}$ However, a thorough history-taking, specifically with regards to recent exposure to certain drugs, can help to confirm the diagnosis. In addition, the new World Health Organization-Uppsala Monitoring Centre scale may help to determine aetiology in such cases. ${ }^{8}$ Clinicians should be aware of rare cutaneous reactions to common drugs often used in clinical practice, such as that observed in the current case with diclofenac.

\section{References}

1. Augustine M, Sharma P, Stephen J, Jayaseelan E. Fixed drug eruption and generalised erythema following etoricoxib. Indian J Dermatol Venereol Leprol 2006; 72:307-9. doi: 10.4103/03786323.26732.

2. Jain SP, Jain PA. Bullous fixed drug eruption to ciprofloxacin: A case report. J Clin Diagn Res 2013; 7:744-5. doi: 10.7860/ JCDR/2013/4757.2901.

3. Lin TK, Hsu MM, Lee JY. Clinical resemblance of widespread bullous fixed drug eruption to Stevens-Johnson syndrome or toxic epidermal necrolysis: Report of two cases. J Formos Med Assoc 2002; 101:572-6.

4. Hsiao CJ, Lee JY, Wong TW, Sheu HM. Extensive fixed drug eruption due to lamotrigine. Br J Dermatol 2001; 144:1289-91. doi: 10.1046/j.1365-2133.2001.04266.x.

5. Fathallah N, Ben Salem C, Slim R, Boussofara L, Ghariani N, Bouraoui K. Acetaminophen-induced cellulitis-like fixed drug eruption. Indian J Dermatol 2011; 56:206-8. doi: 10.4103/00195154.80419.

6. Deepalatha C, Prasad RV, Chandra S, Mohan PM, Lakshmi V. Diclofenac-induced urticaria in paediatric patient. Asian J Pharm Clin Res 2013; 6:1-2.

7. Naranjo CA, Busto U, Sellers EM, Sandor P, Ruiz I, Roberts EA, et al. A method for estimating the probability of adverse drug reactions. Clin Pharmacol Ther 1981; 30:239-45. doi: 10.1038/ clpt.1981.154.

8. Gupta LK, Beniwal R, Khare AK, Mittal A, Mehta S, Balai M. Non-pigmenting fixed drug eruption due to fluoroquinolones. Indian J Dermatol Venereol Leprol 2017; 83:108-12. doi: 10.4103/0378-6323.190890. 